\title{
A HISTÓRIA ENTRE TEMPOS: FRANÇOIS HARTOG E A CONJUNTURA HISTORIOGRÁFICA CONTEMPORÂNEA*
}

\author{
History between Times: \\ François Hartog and the Contemporary \\ Historiographical Context
}

Fernando Nicolazzi**

\begin{abstract}
RESUMO
Este ensaio procura apresentar uma leitura de alguns trabalhos recentes do historiador francês François Hartog, visando expor suas incursões sobre a cultura histórica contemporânea a partir de algumas noções-chave por ele utilizadas, tais como regimes de historicidade e presentismo, situando tal perspectiva no âmbito geral de uma história da historiografia.

Palavras-chave: François Hartog; regimes de historicidade; presentismo.

ABSTRACT

This essay presents a reading of some recent works of French historian François Hartog, in order to expose his incursions in the contemporary historical culture, from some of the key concepts used by him, such as regimes of historicity and presentism, placing such a perspective within the general framework of a history of historiography.
\end{abstract}

Key-words: François Hartog; regimes of historicity; presentism.

Agradeço a Mateus Henrique de Faria Pereira pela leitura de uma versão prévia deste ensaio e pelas sugestões e críticas feitas. Este artigo é o resultado de uma série de notas de aulas ministradas tanto na graduação como na pós-graduação em História da Universidade Federal de Ouro Preto.

** Doutor em História pela UFRGS. Professor do Departamento de História da Universidade Federal de Ouro Preto. 
"Conscientes de seus fundamentos narrativos e poéticos, as práticas historiográficas se inscrevem desde então em uma tensão entre solicitações do presente e peso da tradição, com sua exigência de memória."

Claude Calame ${ }^{1}$

"O que ver quando se pode tudo ver?"

François $\operatorname{Hartog}^{2}$

$I$.

Um evento trivial do cotidiano midiático pode servir de ensejo para este artigo. O esportista, um nadador, atinge a perfeição possível do esporte que pratica, segundo o comentarista que narra estarrecido o seu desempenho. Sob certo ponto de vista, a imagem televisiva é tão significativa quanto a fala do narrador. Há uma linha vermelha que recorta o espaço fluido da piscina, indicando a cronometria conhecida, fundada na melhor marca - a mais rápida - até então realizada. $\mathrm{O}$ nadador, atravessando a barreira do tempo, encontra-se posicionado adiante da linha, como se, de alguma maneira, fosse possível ser mais rápido que a própria contagem do tempo. Antes mesmo que sua mão toque a borda da piscina, assegurando o recorde, a medalha e, sobretudo, o fim da prova, a narrativa já adverte o espectador que aquele é um "momento histórico"; o atleta que o realiza, superando a marca cronométrica, surge na fala empolgada do comentarista como indivíduo "fazendo a história" e que, como consequência direta do fato, acaba também por "entrar para a história". Entre a aceleração que parece fazer o ato chegar primeiro que o tempo e o discurso que decreta a história realizada antes mesmo que o evento se torne "completo" (o termo francês révolu parece indicar melhor a ideia, pois trata daquilo que está acabado e também daquilo que não existe mais), entre o fazer e o entrar n. 173,2005 , p. 11 .

1 CALAME, Claude. "Pour une anthropologie des pratiques historiographiques". L'Homme,

2 HARTOG, François. "Préface". In: Évidence de l'histoire. Ce que voient les historiens. Paris: Éditions EHESS, 2005, p. 15. 
para a história, descortina-se, no âmbito banal da televisão, uma experiência que parece caracterizar parte da cultura histórica na atualidade.

Atento às pressões do contemporâneo, François Hartog há alguns anos se esforça, senão em explicar a complexidade da situação atual (e essa provavelmente não seria sua pretensão), pelo menos na tarefa de oferecer instrumentos conceituais para se pensar e se escrever tanto sobre o quanto no presente. Dois termos correlatos e convergentes aparecem como significativos do esforço salientado: presentismo e regime de historicidade. Ambos passaram pelo crivo de seu olhar analítico, um olhar de historiador cabe frisar, no livro publicado em 2003, Régimes d'historicité. Présentisme et expériences du temps, dentro de uma coleção cujo título é também representativo do momento: La librairie $d u X X I^{e}$ siècle. Como se ressalta nas palavras utilizadas no título, o tempo funciona como uma espécie de eixo norteador através do qual o olhar se desenvolve, olhar que, em uma única expressão, pode-se dizer que atravessa o tempo. A obra posterior, de 2005, Anciens, modernes, sauvages, mantém a dimensão temporal como orientadora do seu procedimento historiográfico. E o mesmo "olhar historiador" por ele assumido ocupa um lugar de destaque na reflexão como algo que, na sua por vezes ilusória evidência, aparece como podendo e devendo ser pensado, isto é, desnaturalizado, e, ainda assim, pensado no tempo, como se mostra no livro do mesmo ano, Évidence de l'histoire. Ce que voient les historiens ${ }^{3}$.

$\mathrm{O}$ escopo deste artigo não é o de realizar uma síntese destas três obras recentes e relativamente conhecidas no Brasil, embora, infelizmente, ainda não traduzidas em edições brasileiras ${ }^{4}$. A tarefa já foi realizada de

3 HARTOG, François. Régimes d'historicité. Présentisme et expériences du temps. Paris: Éditions du Seuil, 2003; HARTOG, François. Anciens, modernes, sauvages. Paris: Galaade Éditions, 2005; HARTOG, François. Évidence de l'histoire. Ce que voient les historiens. Paris: Éditions EHESS, 2005.

4 Entre os livros brasileiros de François Hartog, cabe ressaltar o mérito da coletânea de artigos organizada por José Otávio Guimarães Os antigos, o passado e o presente. Brasília: Editora da UnB, 2003; do livro apresentado por Manoel Luiz Salgado Guimarães, O século XIX e a história. O caso Fustel de Coulanges. Rio de Janeiro: Editora da UFRJ, 2003; além de $O$ espelho de Heródoto. Ensaio sobre a representação do outro. Belo Horizonte: Ed. da UFMG, 1999; A história de Homero a Santo Agostinho. Belo Horizonte: Editora da UFMG, 2001; e Memória de Ulisses. Narrativas sobre a fronteira na Grécia antiga, todos traduzidos por Jacyntho Lins Brandão. Existem ainda alguns textos publicados em periódicos, dentre os quais menciono "O tempo desorientado. Tempo e história: 'como escrever a história da França". Anos 90, Porto Alegre, n. 7, julho de 1997; "Tempo, história e a escrita da história: a ordem do tempo". Revista de História, n. 148, 2003, p. 9-34, e "Tempo e patrimônio". Varia História, v. 22, n. 36, jul./dez. 2006, p. 261-273. Ver ainda a entrevista com o autor, realizada em 1999 e publicada em Scripta Clássica. Literatura, filosofia e história na antiguidade, n. 1, abril 2003. 
forma mais compreensiva do que seria aqui possível ${ }^{5}$. O que me interessa neste ensaio é esboçar algumas notas sobre uma das muitas dimensões que assume a obra em andamento do historiador francês, a saber, a dimensão do tempo presente em sua reflexão. Os três livros mencionados funcionam como arestas que recortam um espaço não fechado onde o contemporâneo, à luz de outras temporalidades ou regimes de historicidade, pode ser representado. Trata-se de ler tais textos fundamentalmente como obra de um historiador (da história), o que não compromete sua leitura como trabalho de um pensador do presente. Em outras palavras, compreender como, a partir de uma visada propriamente historiográfica, isto é, de uma história da historiografia preocupada em articular temporalidades diversas (antigos, modernos, selvagens), o historiador pode operar uma intervenção intelectual em seu próprio tempo, situando-se no e pensando o presente. Nas suas palavras, indagar "como, no sentido próprio do termo, habitá-lo?"6 ou ainda, como vislumbrar "des manières d'être au temps", sobretudo em um tempo presente que se mostra como "inquietude"??

II.

Paul Ricoeur já advertiu, em se tratando das relações entre memória e história, que se toda origem é mítica, todo começo é histórico.

5 Sobretudo em LENCLUD, Gérard. "Traversées dans le temps". Annales HSS, n. 5, septembre-octobre 2006, p. 1053-1084; mas também em SCHAUB, Jean-Frédéric. "L'historiographie est une anthropologie. À propos de trois livres de François Hartog”. Critiques Internationales, v. 4, n. 33, 2006 , p. $183-187$.

6 HARTOG, François. Régimes d'historicité, op. cit., p. 20. Sobre a metáfora do tempo como espaço a ser habitado, remeto às belas páginas de Paul Ricoeur ("L'espace habité"), nas quais se ressalta que "a inquietante estranheza ligada ao sentimento de não estar em seu lugar, mesmo em sua própria casa, nos assombra, e isso seria o reinado do vazio. Mas existe uma questão do lugar porque o espaço tampouco está cheio, saturado. Para dizer a verdade, é sempre possível, e frequentemente urgente, deslocar-se, com o risco de ser esse passageiro, esse caminheiro (randonneur), esse flanêur, esse errante que a cultura contemporânea estilhaçada põe em movimento e ao mesmo tempo paralisa". RICOEUR, Paul. La mémoire, l'histoire, l'oubli. Paris: Gallimard, 2000, p. 185.

7 BLOCKER, Déborah; HADDAD, Elie. "Le présent comme inquiétude: temporalités, écritures du temps et actions historiographiques". Revue d'Histoire Moderne et Contemporaine, n. 53, 2006, p. 160-169. 
Pois o começo aqui também assume, de certa maneira, ares que o colocam avizinhado do mito. O percurso se inicia com uma passagem crucial: o prólogo das investigações de Heródoto, pai fundador do espaço de saber onde os historiadores, mas não só eles, costumam se situar. "Se ele é, conforme a fórmula de Cícero, o 'pai da história', o prefácio (prooímion) de suas Histórias representa a certidão de nascimento desta"8. A memória disciplinar (e disciplinada) da historiografia identifica ali o seu começo e também a sua origem. Todavia, ainda que na obra de Hartog Heródoto ocupe uma posição inicial como objeto de sua pesquisa de doutorado, não é de forma alguma com a pretensão de reforçar a evidência dessa memória. Como ele provocativamente já sugeriu, na prática da escrita da história os gregos foram os "últimos a chegar". Portanto, se Heródoto não é de fato e de direito o "pai da história", é possível sustentar pelo menos que ele seja o "primeiro historiador" .

Nesse sentido, Hartog se dedicou a estudar a obra herodotiana não para encará-lo sob a forma imponente e pesada da figura paterna, mas considerando-o como momento definidor de uma modalidade de saber, de um lugar de produção discursiva até então inédito. Em seu livro, publicado originalmente em 1980, Le miroir d'Hérodote. Essai sur la représentation de l'autre, a obra do primeiro historiador é colocada como ponto da cultura ocidental ao qual se retorna, na intenção permanente de "dar a ler esses textos, reconstruindo - para falar como a hermenêutica - a questão à qual eles respondem, redesenhando os horizontes de expectativa em que, desde seu primeiro dia até os nossos (ainda que no modo de ausência), eles vieram inscrever-se, recalculando as apostas que fizeram e significaram, apontando os quiproquós que sucessivamente provocaram"10.

No longo trajeto que percorre até o século $\mathrm{V}$ a.C., e mesmo alguns séculos antes, já que a história de Heródoto é percebida a partir da matriz épica de Homero, Hartog reafirma o ponto a partir do qual a observação é feita, isto é, o seu próprio presente. A distância no tempo cria, por conseguinte, as condições de possibilidade para uma "experiência de leitura", em

8 HARTOG, François. A história de Homero a Santo Agostinho, op. cit., p. 43.

9 HARTOG, François. "Primeiras figuras do historiador na Grécia: historicidade e história". In: Os antigos, o passado e o presente, op. cit., p. 11-34.

10 Trecho que consta no prefácio à segunda edição do livro, revista e aumentada, de 1991. HARTOG, François. O espelho de Heródoto, op. cit., p. 16. 
um momento (final dos anos 1970) em que os historiadores, escritores da história, "aprendiam a ler". Duas dimensões deste presente lhe aparecem como decisivas: a proximidade com a antropologia, ou seja, as perspectivas abertas pelo estudo da antropologia histórica, e a análise estrutural dos textos, onde os princípios de enunciação dos discursos emergiam como problemas de pesquisa. Um livro em particular é mencionado como significativo do contexto: L'écriture de l'histoire, de Michel de Certeau, participante do júri de arguição da tese, fora publicado quatro anos antes da sua defesa. Ou seja, Hartog situa com precisão o problema de fundo que alimenta sua curiosidade intelectual há já algumas décadas, a saber, as condições culturais e epistemológicas da escrita da história como um saber sobre o outro. Não é demais lembrar que a década de 1970 trouxe à luz ainda, além do livro de Certeau, o Comment on écrit l'histoire (1971 e 1978), de Paul Veyne, e o Metahistory. The historical imagination in nineteenth-century Europe (1973), de Hayden White.

Essa visada retrospectiva e antropológica em direção ao mundo antigo, sem perder de vista o próprio momento histórico em que ela se deu, é constitutiva de sua obra acadêmica. Suas páginas, como o próprio autor chega a comentar, são feitas recorrentemente desses "allers et retours entre des temps différents"; idas e vindas que, percorrendo os tremores no tempo, as "brechas", segundo sua apropriação dos escritos de Hanna Arendt, organizam a coerência de uma reflexão ${ }^{11}$. Na introdução ao Anciens, modernes, sauvages, Hartog indica a tripla dimensão de seu trabalho:

Ao lado dos livros que, relevando de uma história cultural do mundo antigo, trouxeram consigo o vivo da interrogação sobre a alteridade e sobre a fronteira, ao lado dos meus trabalhos sobre a escrita da história tanto antiga quanto moderna (como e por que não se cessou de escrever a história, não a mesma, mas ainda assim a história?), há lugar, depois de muito tempo, para uma terceira janela sobre os usos e as apropriações modernas da Antiguidade [...],

11 Voltando ao parágrafo inicial deste artigo, é preciso ainda mencionar a indagação posta por Hartog: "a imagem do nadador ou mesmo aquela da brecha são adequadas para o nosso contemporâneo?". HARTOG, François. Régimes d'historicité, op. cit., p. 208. 
uso de que ele próprio, pode-se dizer, é praticante ${ }^{12}$. Três elementos que não parecem tratar senão de uma única e mesma coisa: a diferença, a escrita, o tempo, convergem todos para o âmago do saber histórico, nas suas variadas e comumente antagônicas formas de elaboração.

Presente e passado, mas sem deixar de lado certa noção de futuro. Não é gratuito o fato de que, no mesmo livro voltado para a tríade antigos, modernos e selvagens, longas páginas desenvolvem temas candentes para o ambiente intelectual em que um historiador francês na virada do milênio poderia se encontrar: a ideia de Europa, o conceito de democracia, a noção sobre o político, a dimensão do espaço público. Mais do que prognósticos, é um futuro do passado o que se vislumbra. Evidentemente, não se trata tão somente de uma resposta a uma situação de impasse ou de uma simples tomada de posição, projetando ao porvir expectativas morais; a questão é tanto mais complexa, já que envolve criar as condições para situar o tempo presente no tempo, isto é, em relação ao passado e a um (in)determinado futuro.

Historiador mais do que intelectual de plantão, François Hartog faz do seu trabalho um mecanismo de visibilidade sobre o mundo contemporâneo. Mas se trata de um mecanismo sutil e erudito, pois envolve a paciência de percorrer distâncias profundas apartadas no tempo. A sutileza demanda erudição: como ler no contexto contemporâneo, sobretudo o contexto europeu das medidas anti-imigração, a história da democracia ateniense? Difícil resposta. Mas a própria indagação o faz pensar quando, relativizando a perspectiva de Atenas como uma "cité ouverte", sugere com ênfase que ainda assim é equivocado acreditar que "democracia e exclusão do estrangeiro estiveram e devem estar ligados" ${ }^{\prime 13}$. O certo é que o problema não se resume simplesmente a tirar lições dos tempos de outrora em proveito da atualidade ou do porvir. Não se está mais sob a sombra da historia magistra vitae; o registro é outro. Tanto passado quanto presente e futuro aparecem de forma distinta no contexto dessa reflexão.

p. 20-21.

12 HARTOG, François. "Introduction". In: Anciens, modernes, sauvages, op. cit., p. 166.

13 HARTOG, François. “Cité et alterité”. In: Anciens, modernes, sauvages, op. cit., 
É inegável que o passado não chega ao presente apenas na expressão pura de uma herança legada. Ele é igualmente constituído enquanto tal $a$ posteriori, por opções voluntárias ou por escolhas traumáticas, não importa; o que aqui se leva em consideração é a constatação de que há condições de possibilidade para se falar isto ou aquilo, deste ou daquele passado, que não obedecem senão a demandas que lhe são posteriores - uma visada retrospectiva, mesmo que com expectativas de futuro implícita ou explicitamente definidas. Invertendo a rotina do tempo natural, na história e para os historiadores, é o presente quem fala ao passado, e não o contrário. Diante da escrita historiográfica, o passado emudece, está morto e, em muitos casos, enterrado. Hartog, como se sabe, é leitor constante de Certeau ${ }^{14}$. Mesmo em Michelet, frequente atravessador do "rio dos mortos" e referência permanente em seus trabalhos, ressuscitar não significava fazer reviver aqueles que já passaram, "mas fazer aparecer a verdade de suas vidas passadas"15.

Esse olhar contemporâneo dirigido ao passado, por sua vez, coloca em primeiro plano as possibilidades, tanto positivas quanto negativas, dos usos viáveis do passado pelo presente, isto é, a dimensão pública da história, não limitada apenas aos profissionais da disciplina. Em uma expressão, trata-se de se pensar "os usos políticos do passado". Tal o intuito de Hartog, conjuntamente com Jacques Revel, na direção da coletânea Les usages politiques du passé. O título certamente não deve levar ao engano, pelo plural dos usos em relação ao singular do objeto utilizado; afinal, formas de utilização distintas implicam, cada qual à sua maneira, definições variadas dos passados que estão em jogo. É como se o plural do primeiro termo passasse a contaminar o segundo. Corolário disso tudo, como não

14 Para quem o historiador, acalmando os mortos, constrói através de sua escrita "túmulos escriturários". CERTEAU, Michel de. L'écriture de l'histoire. Paris: Gallimard, 1975, p. 8. Ver ainda o comovente relato que serve de epílogo ao Évidence de l'histoire, onde Hartog confidencia: "ele seria antes aquele ao contato de quem eu comecei a compreender que a história iria se tornar a questão de uma vida", op. cit., p. 237.

15 HARTOG, François. "Michelet, la vie, l'histoire". In: Évidence de l'histoire, op. cit., p. 159 (há uma versão traduzida para o português: "Michelet, a história e a "verdadeira vida"”. Ágora. Revista de História e Geografia, v. 13, n. 1, janeiro-junho 2005, p. 13-20 - dossiê "Historiografia e Escrita da História", organizado por Temístocles Cezar). 
poderia deixar de ser, é a própria pluralidade das perspectivas de escrita da história. Do livro em questão, contudo, não retenho senão as páginas finais do texto de apresentação escrito a quatro mãos pelos organizadores, intitulado significativamente "Nota de conjuntura historiográfica".

Uma indagação sobre a atualidade organiza as considerações ali elaboradas: "a quais novas questões o historiador é confrontado?". $\mathrm{Na}$ sequência do raciocínio, chega-se ao ponto crucial do argumento, "o primado do 'contemporâneo' ou do 'presente' como categoria dominante seria o primeiro sinal dessa conjuntura" ${ }^{6}$. Um dos indícios mais visíveis da situação é a ênfase disciplinar em uma história do tempo presente, que na França institucionalizou-se como tal na década de 1970 através de um centro de pesquisas vinculado ao Centre National de la Recherche Scientifique (CNRS). A relativa proximidade com o contexto da segunda grande guerra, as marcas ainda visíveis nos espaços públicos e nas consciências íntimas dos indivíduos (e mesmo nos corpos das vítimas), mantinham os episódios traumáticos do confronto no centro de diversas discussões historiográficas relativas a este passado recente, que parecia "não querer passar"17. Assim, os historiadores passam a ocupar o "terreno do contemporâneo", também frequentado por outros profissionais interessados em desvendá-lo, como, por exemplo, os cientistas políticos e os jornalistas.

Ou seja, essa vertente de investigação historiográfica voltada para a contemporaneidade dialoga diretamente com a dimensão memorial que o debate assume. Presente e memória, palavras-chave dessa conjuntura, estabelecem o pano de fundo para a reaparição de uma figura emblemática para o saber histórico, deslocada durante o oitocentos em função da ênfase nos documentos escritos como fontes privilegiadas para o historiador (à exceção notória de Michelet, como sugere Hartog), mas que, na segunda metade do século XX, retornou com seu estatuto ético e epistemológico problematizado: a testemunha. "Uma testemunha, hoje, é antes de mais nada a voz e o rosto de uma vítima, de um sobrevivente que se escuta, que

16 HARTOG, François; REVEL, Jacques. "Note de conjoncture historiographique". In: HARTOG, François; REVEL, Jacques (sous la direction de). Les usages politiques du passé. Paris: Éditions de l'École des Hautes Études en Sciences Sociales, 2001, p. 20.

17 Ver, entre outros, o dossiê "L'histoire du temps présent, hier et aujourd'hui". Bulletin de l'Institut d'Histoire du Temps Présent, n. 75, juin 2000. O IHTP é herdeiro do Comité d'Histoire de la Deuxième Guerre Mondiale, que havia sido criado no início da década de 1950. 
se faz falar, que se registra e que se filma"18. Ela torna possível uma certa história, ligada desde o seu princípio ao papel da memória. Para Paul Ricoeur, por exemplo, o relato testemunhal se encontra no início do processo epistemológico que subsidia o conhecimento histórico ${ }^{19}$. A atenção a essa figura, por sua vez, conduz a uma reflexão propriamente historiográfica, no sentido de "questionar o papel deste personagem banal, familiar e, no entanto, estranho, que é o historiador em nossas sociedades"

É na espessura histórica dessa figura, nas múltiplas feições por ela assumidas desde a epopeia homérica até a expressão dolorosa dos sobreviventes (superstes, o que "subsiste além") no pós-guerra, que Hartog desdobra parte da situação atual que se coloca para a história. Encarada nestes termos, essa figura que atualmente se faz parecer tão natural, situada entre o plano da oralidade e o da escrita, quando transformado em gênero livresco, dotou a discussão de uma amplitude até então impensada (e talvez, para alguns, indesejável). Isso acabou por empurrar os historiadores para o espaço público no qual o debate se trava, desde então, não mais apenas entre os seus próprios pares. Do papel moral da testemunha caminha-se, desse modo, à função social dos historiadores (e mesmo do historiador enquanto testemunha, como se verá mais adiante); e da constatação dos usos possíveis do passado, indaga-se que usos são esses, a quem é dado o direito e a quem cabe o dever sobre esses usos. Entre a ética e a epistemologia, abre-se a noção da legitimidade do discurso voltado ao passado, pois se o testemunho pode ser "arquivado", ele permanece sendo algo a mais do que uma simples "fonte oral"21. Daí a posição cautelosa de Hartog diante do problema:

A testemunha de hoje é uma vítima ou descendente de uma vítima. Esse estatuto de vítima fundamenta sua autoridade e

18 HARTOG, François; REVEL, Jacques (sous la direction de). "Note de conjoncture historiographique". In: Les usages politiques du passé, op. cit., p. 21.

19 "Com o testemunho se abre um processo epistemológico que parte da memória declarada, passa pelo arquivo e os documentos, chegando por fim à prova documental". RICOEUR, Paul. La mémoire, l'histoire, l'oubli, op. cit., p. 201.

20 HARTOG, François. "Le témoin et l'historien". In: Évidence de l'histoire, op. cit., p. 192 (versão em português, "O testemunho e o historiador". In: PESAVENTO, Sandra (Org.). Fronteiras do milênio. Porto Alegre: Editora da UFRGS, 2001, p. 11-43).

21 Ver sobre isso SARLO, Beatriz. Tiempo pasado: cultura de la memoria y giro subjetivo. Una discusión. Buenos Aires: Siglo XXI Editores, 2005. 
alimenta a espécie de temor de reverência que por vezes a acompanha. De onde o risco de uma confusão entre autenticidade e verdade, ou pior, de uma identificação da segunda com a primeira, enquanto que a distância entre a veracidade e a fiabilidade de um lado, a verdade e a prova de outro, deveria ser mantida ${ }^{22}$.

Afinal, como a reflexão profunda de Ricoeur já sugeriu (e o filósofo é justamente mencionado no texto), a fidelidade da memória e a veracidade da história mantêm estreita ligação, mas não chegam a se justapor por completo.

IV.

A inserção quase que compulsória dos historiadores dentro do espaço público, mesmo que à revelia de alguns, acrescenta outra e significativa dimensão para o debate: as questões jurídicas que dizem respeito aos usos políticos do passado e que tocam diretamente na questão ética da "justa memória". História e justiça, o historiador e o juiz, termos que, conhecidos desde sempre, há algum tempo foram colocados em nova evidência ${ }^{23}$. Não há como deixar de fazer menção aqui ao livro publicado originalmente em 1991, em que Carlo Ginzburg coloca um diante do outro dois procedimentos epistemologicamente tão próximos, mas com implicações sociais profundamente díspares. O historiador italiano demonstra as distorções realizadas entre o inquérito dos fatos, a administração das provas e a decisão jurídica no processo judicial sofrido por seu amigo Adriano Sofri, acusado em 1988 de haver incentivado "um homem a matar outro", dezesseis anos antes. Sofri foi condenado em 1990 a vinte e dois anos de reclusão.

22 HARTOG, François. "Le témoin et l'historien". In: Évidence de l'histoire, op. cit., p. 213.

23 Antes de mais nada, para a idade da questão, remeto ao capítulo V de $A$ história de Homero a Santo Agostinho, intitulado “O advogado e o historiador", p. 143-186. Ver ainda os dossiês contemporâneos: "Vérité judiciaire, vérité historique". Le Débat, n. 102, novembre-décembre 1998; e "Forum on historians and the courts". History and Theory, n. 41, october 2002. 
Ginzburg, que terminou de escrever o texto apenas alguns meses após a sentença, na pressão que a atualidade lhe colocava, salienta que escreveu por duas razões principais e que acabam por definir dois autores distintos para o mesmo escrito: a razão pessoal, da amizade e da certeza íntima na inocência do réu, convoca para as páginas do livro a figura do cidadão, no exercício político e público do debate; a razão "profissional", digamos assim, traz para o discurso o personagem do historiador, na análise meticulosa de um procedimento técnico: o manejo das provas, das evidências policiais e dos argumentos jurídicos. Cidadão e historiador, encorpados na mesma pessoa e no mesmo nome de autor, colocam-se, dessa maneira, diante do terceiro elemento da questão, isto é, o juiz. Ginzburg faz questão de indicar na introdução que ele não assume no livro a posição de uma "testemunha" para a defesa de Sofri e que, por essa mesma razão, o caminho que percorre no intuito de "convencer da sua inocência", a construção de seus argumentos é toda ela de feição diferente da de um depoimento; trata-se sim de um trabalho de historiador. Das relações entre história e direito, ou mesmo para a problemática da justiça na história, Ginzburg ressalta a distância que separa ambas as práticas: "reduzir o historiador ao juiz é simplificar e empobrecer o conhecimento histórico; mas, reduzir o juiz ao historiador, é perverter irremediavelmente o exercício da justiça"24.

As relações entre história e justiça se encontram na condição de fundamentos para o saber histórico moderno. Entretanto, as questões atualmente colocadas assumem características que tornam singular a discussão contemporânea. Afinal, o saber histórico em diversas ocasiões acaba por assumir as vezes de "perícia técnica" sobre o passado ${ }^{25}$; ou, em uma perspectiva com implicações bastante distintas, sobre a maneira pela qual o presente encara o passado $^{26}$. Ainda quando há uma recusa peremptória dessa função técnica para

24 GINZBURG, Carlo. Le juge et l'historien. Considérations en marge du procès Sofri. Paris: Éditions Verdier, 1997, p. 118.

25 Ver o relato de Marc Olivier Baruch sobre sua participação, na qualidade de historiador, como testemunha no processo levantado contra Maurice Papon, em 1997 (os termos em itálico foram usados na carta que o procurador geral de Bordeaux enviou a Baruch). BARUCH, Marc Olivier. "Procès Papon: impressions d'audience". Le Débat, n. 102, novembre-décembre 1998, p. 11-16.

26 É o caso do historiador inglês Richard Evans, chamado para "periciar" a obra de um autor (o também inglês David Irving) acusado de negacionismo, onde ele encontrou diversas manipulações de informação e falsificações de evidências. Ou seja, o que se julga é a visão voltada para o passado, não atos realizados no passado. Ver as considerações sobre o processo em EVANS, Richard. "History, memory, and 
o historiador, no que se refere a situações específicas, obviamente, as consequências da atitude mostram a complexidade da questão. Como se sabe, Henri Rousso recusou-se a participar do processo movido contra Paul Touvier, alto funcionário do governo Vichy, em que era acusado de crime contra a humanidade. Ainda que convencido da participação de Touvier no assassinato de sete prisioneiros judeus em 1944, Rousso não concordou com a narrativa sobre o fato que acabou vigorando durante o processo: no caso preciso mencionado, tratando-se de uma questão "interna" entre franceses, Touvier teria agido muito mais por um sentido de vingança pessoal do que como colaborador dos nazistas, como ficou decidido na corte, "o que era não apenas falso historicamente, mas também pouco significativo em relação à memória", nas palavras de Rousso. Pierre-Yves Gaudard resumiu de forma lapidar o problema: "a condenação à perpetuidade de Touvier, marcada por uma evidente legitimidade moral, não estando menos fundada sobre uma mentira histórica"27.

A recusa de Rousso é significativa, nesse sentido, por deixar às claras as não tão evidentes relações entre legitimidade moral e verdade histórica, as quais não são nem devem ser necessariamente justapostas. Os limites, porém, e as consequências de tal definição nem sempre são agradáveis ou livres de qualquer implicação política mais importante. Para vítimas ou parentes de vítimas, a noção ali de "mentira histórica" certamente adquire diferentes proporções. Mas o historiador francês atribui ainda sua posição a outro motivo também relevante para essa discussão: o fato de que ele, na condição de historiador, apenas atuaria no momento posterior àquele que decididamente caracteriza a prática historiográfica, a saber, o momento do arquivo. Rousso não teria acesso às provas, aos indícios, não poderia estabelecer a crítica às evidências. Nesse sentido, sem poder de fato atuar como historiador, no âmago do seu ofício, sua participação no processo seria inadequada.

François Hartog, em diversas oportunidades, interveio na discussão. No mesmo dossiê publicado pelo Le Débat, em 1998, ele insere um artigo com o título de "O historiador e a conjuntura historiográfica", onde

the law: the historian as expert witness". History and Theory, n. 41, october 2002, p. 326-345, cujo ensejo é, na verdade, uma resenha sobre a entrevista de Henri Rousso publicada em La hantise du passé: entretien avec Philippe Petit. Paris: Éditions Textuel, 1998.

27 GAUDARD, Pierre-Yves. "L'historien et le prétoire". Le Débat, n. 102, novembre-décembre 1998, p. 42. 
indagou se tal conjuntura indicaria "alguma coisa de novo na postura, na prática e quase na epistemologia do historiador do tempo presente ou do historiador tout court" ${ }^{28}$. Como ele ainda sugere, perguntar-se, na atual cultura histórica, "quem é historiador?" há muito deixou de ser uma questão puramente acadêmica. Sobretudo, cabe indagar a partir de onde e quem tem o direito de definir tal ou tal pessoa como historiador. Hartog situa o problema história-justiça/historiador-juiz da seguinte maneira: "antes de saber se o historiador é ou não é um juiz (e que juiz?), vale a pena refletir sobre que pode significar julgar do ponto de vista histórico" 29 . O guia para suas reflexões neste caso é Charles Péguy, dreyfusard que, não sendo propriamente historiador, foi aquele que, na França entre 1897 e 1914, "mais refletiu e escreveu sobre história". O tema levantado aponta para a atuação do historiador dentro do espaço público. Entre a testemunha e o perito, a questão do julgamento histórico desponta não apenas para o uso político do passado, mas também para o uso social da história.

Hartog situa toda a discussão no plano da temporalidade. Se julgar um indivíduo cujos atos foram cometidos no passado, pelo menos num passado já separado por décadas, obedece a uma demanda não apenas por justiça, mas também por memória, definir juridicamente a imprescritibilidade de determinados atos revela os traços de uma experiência particular de tempo. Para ele, o imprescritível, do ponto de vista jurídico, faz do ato cometido um ato sempre no presente, pois é como se o tempo não agisse sobre o fato: ele deve estar sempre disponível à lei. Nesse sentido, pode-se dizer que "nós vivemos enfim em um tempo de presentismo forte, onde um presente onipresente e hipertrofiado pretende não ter outro horizonte senão ele mesmo. Espécie de presente eterno, ansioso por dominar o tempo ou, do mesmo modo, de o suprimir, nosso tempo se emprega a realizar a demonstração de sua superioridade moral sobre o passado, bem como a antecipar o julgamento que a posteridade lhe dirigirá. O historiador (do presente, mas não apenas ele) se encontra, em todo caso, preso, como cada um, dentro do círculo do presente" 30 .

28 HARTOG, François. "L'historien et la conjoncture historiographique”. Le Débat, n. 102, novembre-décembre 1998, p. 5.

29 HARTOG, François. "Conjoncture fin de siècle: l'évidence en question?". In: Évidence de l'histoire, op. cit., p. 223.

30 HARTOG, François. "L'historien et la conjoncture historiographique", op. cit., p. 10. 
Entre a moral da história, aquela que se arroga o direito de deliberar juridicamente sobre o passado, e a justa memória, que coloca um imperativo ético sobre o modo como o passado pode ser apreendido, o problema incide notadamente sobre o papel do historiador na sociedade contemporânea, no presente. A formulação de Paul Ricoeur oferece uma possível resposta para o impasse: "é ao juiz que cabe condenar e punir, e ao cidadão de militar contra o esquecimento e também em favor da igualdade de memória; ao historiador resta a tarefa de compreender sem culpar ou desculpar"31.

V.

Presente, memória, testemunho, justiça. Os termos que vêm complementar a discussão são comemoração e patrimônio. Realizado na fronteira mesma entre o dever ou o trabalho de memória e as dimensões do esquecimento (induzido ou inconsciente, quando traumático), o ato de comemorar parece manter suspensa, ainda que por breves instantes, a temporalidade dos fatos; é como se o corte entre passado e presente fosse momentaneamente anulado para que uma comunidade, diante dos seus momentos fundadores, pudesse realizar plenamente o fato de se reencontrar consigo mesma. Há certamente algo de terapêutico nas comemorações, como se elas, de uma ou outra forma, fossem como que momentos de descanso diante da imponência do atual: o passado revisitado oferece a possibilidade do escape e do alívio.

Comemorar, enquanto prática cultural, envolve o trabalho sobre a memória inserido no plano de uma coletividade (co-memorar). Comemorar aparece também como rememoração, o trabalho da memória sobre ela mesma, uma espécie de reatualização de seus princípios (re-memorar). De qualquer forma, a comemoração sempre implicou em uma distância temporal (as datas redondas que denotam o montante de tempo passado: os 30 anos disso, o centenário daquilo etc.), um recorte bem marcado entre passado e presente. De fato, a prática permanece a mesma. Entretanto,

31 RICOEUR, Paul. "L'écriture de l'histoire et la représentation du passé". Annales HSS, n. 4, juillet-août, 2000, p. 744. 
segundo Hartog, há eventos que dão a impressão de conter neles mesmos a sua própria comemoração. $\mathrm{O}$ encaminhamento da ideia, mais uma vez, vem de Charles Péguy, que considerava a tomada da Bastilha como uma festa, uma celebração sobre si mesma. $\mathrm{O}$ extremo disso, como ressalta o historiador, é o evento-limite do 11 de setembro, em que a "repetição" do ato, $\mathrm{o}$ ataque à segunda torre, ocorre quase que concomitantemente ao ato em si, já em transmissão simultânea pela mídia. A história sendo narrada no momento mesmo em que ela ocorre ${ }^{32}$.

A voga comemorativa, por sua vez, segue também acompanhada pela "patrimonialização galopante" das sociedades contemporâneas, sobretudo na Europa, foco da reflexão de Hartog. "Alter ego da memória", o patrimônio é também sinal dos tempos. Se o presentismo é de fato outra modalidade de ordem do tempo, um regime distinto de historicidade, a patrimonialização pode ser o indício de uma crise do tempo. Berlim, a cidade para historiadores, segundo Hartog, acumulando, entre os inúmeros guindastes que despontam em seu céu, diversas camadas de tempo que sedimentam certa experiência histórica, oferece um ponto de observação favorável. A queda do muro, por exemplo, foi seguida pela sua instantânea museificação, enquanto objeto dado a ver e que, de certo modo, faz lembrar. Assim, na urgência do presente e também pelas pressões da memória, do dever-se lembrar, nota-se ainda a propagação de lugares destinados exatamente a essa função, qual seja, estabelecer a ligação entre o plano visível e o invisível, o objeto concreto e a lembrança impalpável: os memoriais. Neles, geralmente se encontra um tipo de anseio pela experiência, um experienciar a história, que torna supostamente possível o reencontro traumático ou benfazejo do presente com o passado.

Hartog faz menção ao United States Holocaust Memorial Museum (note-se a ênfase quase redundante, um "museu memorial") e à pretensão ali transmitida de transformar cada visitante em uma "testemunha vicária". Para tanto, recorre-se a objetos "autênticos" ou, na expressão mais corriqueira, mas não menos problemática, objetos de época, além da elaboração

32 HARTOG, François. "Mémoire, histoire, présent". In: cit., p. 155 e s. Uma das referências constantes de Hartog sobre o assunto é NORA, Pierre. "Entre mémoire et histoire. La problématique des lieux". In: . Les lieux de mémoire. Tomo I. Paris: Gallimard, 2002. Além deste, outro texto de fundamental importância para a discussão, publicado originalmente em 1974, é NORA, Pierre. "O retorno do fato". In: LE GOFF, Jacques; NORA, Pierre. História. Novos Problemas. Rio de Janeiro: Francisco Alves, 1995. 
de formas de interação com o ambiente. O Memorial aos Judeus Mortos da Europa (Denkmal für die ermordeten Juden Europas), em Berlim, é outro exemplo relevante, onde a ordem racional é justamente o que proporciona a intranquilidade da experiência e da lembrança. No Brasil, cabe menção ao Memorial da Resistência, na Estação Pinacoteca em São Paulo. O prédio que o abriga foi, durante mais de quarenta anos, sede do Departamento Estadual de Ordem Política e Social, servindo durante a ditadura como centro de detenção. Sua organização leva a um tipo de experiência-limite, embora o diretor da instituição ressalte o impossível da tarefa: "Essa não é uma vivência que possa ser experimentada. Nem de longe. Não era uma simples

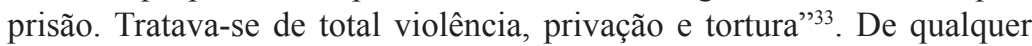
forma, esse exercício mnemônico propiciado pelo memorial torna o lugar patrimônio da memória coletiva, aquilo que deve ser protegido (tombado), preservado e, em sendo o caso, restaurado. Se o memorial não pode, de fato, tornar vivenciável novamente uma experiência traumática, certamente ele sucede no esforço de representar, de acordo com ideias variáveis, essa mesma experiência; ele se encontra, nesse sentido, e valendo-me de um jargão historiográfico, situado entre o campo das práticas e o universo das representações.

Noção ligada historicamente àquela de monumento histórico, o patrimônio contemporâneo expandiu enormemente seu campo de abrangência. Dos espaços urbanos ao meio ambiente, do patrimônio nacional ao patrimônio universal da humanidade, dos objetos culturais aos elementos genéticos, tudo parece lhe servir de pretexto. Dos significados possíveis da situação, Hartog retém alguns pontos importantes. Acima de tudo, o sinal de ruptura, de "brecha" no tempo que ela carrega, assim como sua funcionalidade terapêutica. "O patrimônio é uma maneira de viver as cesuras, de as reconhecer e de as reduzir, reparando, elidindo, produzindo semióforos [...] O patrimônio é um recurso para tempos de crise" ${ }^{34}$. Ele garante, em

33 CARIELLO, Rafael. "Pinacoteca de SP 'recria' porão da ditadura a partir de relatos de ex-presos". Folha de S. Paulo, 05 de fevereiro de 2009.

34 HARTOG, François. "Patrimoine et présent". In:

Régimes d'historicité, op. cit., p. 205. Hartog faz referência à noção de semióforo de Krzysztof Pomian como "objetos visíveis investidos de significados". Assim, "o patrimônio é a reunião de semióforos que uma sociedade, em um momento (e por um momento), se dá” (p. 166). Caberia acrescentar que a noção de patrimônio opera um deslocamento dos significados atribuídos aos objetos, como, por exemplo, a alteração da sua função, isto é, do seu status, de um edifício (uma prisão transformada em espaço de visitação pública). 
momentos de aceleração do tempo, um instantâneo em que o tempo se torna palpável e uma relação temporal surge como possível, mesmo que seja no sentido que segue do presente para o presente: "Este patrimônio é ele mesmo trabalhado pela aceleração: é preciso fazer rápido antes que seja tarde demais, antes que a noite caia e que o hoje não tenha desaparecido completamente" ${ }^{35}$.

\section{$V I$.}

No "círculo do presente", a história, outrora denominada ciência do passado, parece perder toda sua relativa evidência. Afinal, "dizer a "evidência da história' não é já abrir uma dúvida, deixar lugar a uma interrogação: é assim tão evidente depois de tudo?". Do plano ético em que a discussão se encaminhou até aqui, chega-se mais detidamente à sua dimensão epistemológica: "o que implica um fazer da história e, de início, do que e de quem depende isso?" 36 . A voga atual pela "teoria da história" coloca, ela também, um problema a ser pensado: a epistemologia seria para o historiador, tal como predisse Pierre Chaunu, uma "tentação" que é preciso descartar? Aos historiadores não seria demandada, na atuação do seu ofício, uma reflexão sobre as características e os limites da sua prática? O que define o saber histórico enquanto um saber? Para Hartog, nos seus constantes exercícios de uma história da história, epistemologia e historiografia não se constituem como termos opostos. Pelo contrário, para ele, a postura reflexiva sobre a operação historiográfica tende a se encaminhar para uma epistemologia histórica, ou antes, para uma "historiografia epistemológica" que está, nas suas enfáticas palavras, "nos antípodas de uma disciplina ou de uma subdisciplina, constituída ou em constituição, e assunto de alguns especialistas mais ou menos autoproclamados e se autorreproduzindo" ${ }^{37}$.

p. 206.

35 HARTOG, François. "Patrimoine et présent". In: Régimes d'historicité, op. cit.,

36 HARTOG, François. "Préface". In: Évidence de l'histoire, op. cit., p. 11.

37 HARTOG, François. "Conjoncture fin de siècle: l'évidence en question?" In:

Évidence de l'histoire, op. cit., p. 232 (a seção do capítulo traz o subtítulo de "A história tentada pela epistemologia?"). 
Se a historiografia vem há algum tempo se definindo com um campo de pesquisa singular, com seus "lugares", suas "práticas" e suas "escritas" particulares, como é o caso do próprio seminário que François Hartog ministra na École des Hautes Études en Sciences Sociales/EHESS, em Paris, cujo título é "Historiografia antiga e moderna", ela ainda não deixou de ser assunto para historiadores no sentido amplo do termo. Pierre Nora já havia situado a questão nos termos aqui tratados, sugerindo que o advento recente da história da historiografia, fruto da cisão própria do século XX entre história e memória, provocou o despertar de uma "consciência historiográfica", colocando a historiografia em sua "era epistemológica": tratava-se, segundo ele, do "nascimento de um cuidado historiográfico, é a história que se propõe o dever de perseguir nela mesma aquilo que não é ela, descobrindo-se vítima da memória e se esforçando para dela se livrar" ${ }^{\prime 3}$. Afinal, uma história da história, qualquer que seja ela, é e permanece sendo história. O que não invalida, por sua vez, os esforços de reflexão sobre como escrevê-la, qual o estatuto da sua "fonte", qual a natureza da sua indagação, qual a característica de seus procedimentos. A pretensão de Hartog, creio, é a de evitar um hiato, tão pouco proveitoso, entre teoria da história, de um lado, e, de outro, historiografia.

Seu modo de operação indica, em primeiro lugar, um gosto todo particular por aquilo que chamamos (pelo menos aqui no Brasil) de ensaio ${ }^{39}$. Os três livros no início mencionados trazem coletâneas de artigos nos quais se nota o esforço tateante de reflexão, ou antes, da reflexão que lhe acompanha a vida, "a questão da história". Textos geralmente curtos que acabam por formar um calidoscópio de formas que, conforme a maneira pela qual são arranjadas, indicam caminhos distintos de investigação. Todos, entretanto e invariavelmente, trazem como pano de fundo uma reflexão sobre o tempo, sobre as diferentes formas de experiência temporal que caracterizaram a sociedade ocidental em distintos momentos históricos. Nesse sentido, ao pensar o tempo menos como uma categoria filosófica do

38 NORA, Pierre. "Entre mémoire et histoire. La problématique des lieux". In: Les lieux de mémoire, op. cit., p. 26.

39 Segundo suas próprias palavras, trata-se menos de um "ensaísmo" do que de um "interesse pelo ensaio", na definição por ele encontrada em Robert Musil: "um ensaio é a forma única e inalterável que um pensamento decisivo toma à vida interior de um homem". Citado em "Sur la notion de régime d'historicité". In: DELACROIX, Christian; DOSSE, François; GARCIA, Patrick (sous la direction de). Historicités. Paris: Éditions La Découverte, 2009, p. 148. 
que como, segundo o viés antropológico, um artefato cultural que organiza determinadas sociedades, Hartog historiciza a cultura histórica que ainda chamamos de nossa, na ampla duração da sua própria história. Afinal, para o bem ou para o mal, mesmo que já contestada a paternidade, ainda mantemos com o historiador de Halicarnasso certa relação filial (é bem verdade que, em diversos momentos, "matar o pai" nunca se constituiu como problema para muitos historiadores!).

Pensar a história escrevendo história, tal é o procedimento de Hartog. Quer dizer que no momento mesmo em que a história é escrita, a indagação sobre como se pode escrevê-la segue pari passu com sua prática. $\mathrm{Ou}$, antes, ela aparece como parte constitutiva da prática. Tendo, então, o tempo como ensejo para a investigação, a maneira como ela se dá reside na ideia de movimento: "Por conviç̧ão intelectual e por gosto, optei pelo 'movimento que desloca as linhas', privilegiando os limites e os limiares (seuils), os momentos de inflexão ou de retorno, as discordâncias"40. Portanto, aquelas idas e vindas no tempo e no espaço, dos antigos aos modernos, do Pacífico a Berlim, fazem de seus escritos uma espécie de trabalho sobre a diferença. Não é demais considerar aqui que, menos evidente que outros, mas ainda assim presença marcante em suas páginas, Michel Foucault, sempre atento às diferenças e descontinuidades, nelas aparece justamente como convite à reflexão.

Antigos e modernos, o velho par que retorna para alimentar um pensamento sobre o tempo, levando em consideração, notadamente, a ideia de "brechas" na experiência temporal. Não é forçoso pensar que o último meio século gerou uma situação de impasse para o saber histórico contemporâneo. Se se trata de uma "crise" do conhecimento histórico não vem ao caso aqui desenvolver, pois creio que a ideia de uma reorganização dos seus princípios é mais adequada para definir a situação. De todo modo, diante do impasse, diversas respostas se mostram possíveis. Para Hartog, a história antiga - os antigos, mais precisamente - funciona como um recurso analítico para a já referida "questão de uma vida". Não é à toa que ela desponta em sua obra como ponto privilegiado para a reflexão. É o caso, por exemplo, do dossiê

40 HARTOG, François. "Ordres du temps, régimes d'historicité". In: d'historicité, op. cit., p. 29. 
organizado por ele e por Alain Schnapp na revista Annales, em 1982, onde ressalta a afirmação de que, "se a Antiguidade é um outro mundo, a história antiga não é fundamentalmente uma outra disciplina" ${ }^{41}$. Parece-me, portanto, que, mesmo quando seus olhos incidem nos séculos anteriores a nossa era, Hartog mantém em seu campo de visão os problemas que o presente coloca aos historiadores. $\mathrm{O}$ recurso aos antigos permite-o afastar-se do presente para dar a ele outra luminosidade, vê-lo sob outra luz, e oferecer respostas distintas aos embaraços por ele colocados.

Os antigos e os modernos. Mas também alguns "selvagens". E por essas andanças em que a diferença no espaço pode também ser encarada como diferença no tempo, o historiador, como um viajante, tematiza a ordem temporal, mesmo que não seja naquele registro evolutivo e progressivo de tempo sobre o qual Claude Lévi-Strauss, outro autor caro a Hartog, estabeleceu a crítica. Para tanto, pensando a história no momento mesmo em que se a escreve, emerge a questão sobre como escrever a respeito do tempo, quais categorias utilizar, quais os termos mais propícios ao entendimento? Resulta dessas indagações a formulação de uma noção que lhe permite conceituar a experiência de tempo, qual seja, a noção de regime de historicidade. Como o próprio autor já historicizou sua obra, sabe-se que os primeiros lampejos de tal noção apareceram através da relativização cultural proposta por Marshall Sahlins: "outras épocas, outros costumes". Como já foi dito, Hartog sempre manteve um contato bastante próximo com a antropologia ${ }^{42}$. Dessa maneira, foi com um antropólogo, Gérard Lenclud, que ele publicou, em 1993, um dos primeiros textos em que a questão vem sistematizada ${ }^{43}$. Dois anos mais tarde, a noção segue sendo trabalhada, no texto que apareceu na revista $A n$ nales, como noção-chave para refletir sobre as "brechas" no tempo e sobre a ascensão do presente como categoria temporal dominante ${ }^{44}$.

41 HARTOG, François. "Introduction: histoire ancienne et histoire". Annales ESC, v. 37, n. 5, 1982, p. 687 (há uma tradução para o português em HARTOG, François. Os antigos, o passado e o presente, op. cit., p. 187-204).

42 Uma das referências que emerge no livro de 2003 é o trabalho de Johannes Fabian, Time and the other. How anthropology makes its object. New York: Columbia University Press, 1983.

43 HARTOG, François; LENCLUD, Gérard. "Regimes d'historicité". In: DUTU, Alexandre; DODILLE, Norbert. L'état des lieux en sciences sociales. Paris: L'Harmattan, 1993.

44 HARTOG, François. “Temps et histoire: 'comment écrire l'histoire de France?'”. Annales ESC, v. 50, n. 6, 1995, p. 1.219-1.236 (publicado no Brasil em Anos 90, Porto Alegre, n. 7, julho de 1997). 
Pois é em 2003 que a noção cria outra visibilidade com a publicação de Régimes d'historicité. Diferente de um tratado teórico sobre um conceito, o livro reúne ensaios que tornam a noção de regime de historicidade pensável no tempo: do encontro do Capitão Cook com os habitantes do Pacífico no século XVIII, passando pelo pranto de Ulisses junto aos feácios e por Santo Agostinho, atravessando ainda, acompanhado por Chateaubriand, a revolução de 1789 , e chegando ao presente por meio da memória e do patrimônio. Não se trata da obra de um teórico, mas sim da pesquisa de um historiador. É, portanto, no caminho desse percurso historiográfico que a noção se constitui, menos como um conceito explicativo do que como um recurso para a reflexão.

Deixemos a palavra para o autor:

onde situar a noção de regime de historicidade nesta galeria de referências percorridas em passos largos? Sua pretensão é infinitamente mais modesta e seu alcance, se ela tem um, bem mais limitado! Simples ferramenta (outil), o regime de historicidade não pretende dizer a história do mundo passado, e menos ainda aquela do porvir [...] Formulada a partir de nossa contemporaneidade, a hipótese do regime de historicidade deveria permitir o desdobramento de um questionamento de historiador (questionnement historien) sobre nossas relações com o tempo. Historiador, no sentido que ele joga sobre múltiplos tempos, instaurando um vai-e-vem entre o presente e o passado ou, melhor, passados, eventualmente bastante distantes, tanto no tempo quanto no espaço. Este movimento é sua única especificidade. Partindo de diversas experiências de tempo, o regime de historicidade se pretende uma ferramenta heurística, ajudando a melhor apreender não o tempo, todos os tempos ou o todo do tempo, mas principalmente os momentos de crise do tempo, aqui e lá, quando justamente vêm a perder sua evidência as articulações do passado, do presente e do futuro ${ }^{45}$.

45 HARTOG, François. "Ordres du temps, régimes d'historicité". In: d'historicité, op. cit., p. 26 e 27. 
O sinal da modéstia atribuído a tal noção não evitou, contudo, que ela servisse de ensejo para reflexões críticas em diversas ocasiões ${ }^{46}$. Três delas me parecem relevantes para o momento. A primeira é a resenha escrita por Déborah Blocker e Elie Haddad, publicada na Revue d'Histoire Moderne et Contemporaine, em 2006. Hartog aparece nas páginas, ao mesmo tempo, tanto como um historiador nostálgico da história quanto como um estudioso pessimista sobre a situação contemporânea. Suas inquietações em relação ao presente, mas, sobretudo, à sensação de enclausuramento diante de um futuro que se mostra sombrio, faz da sua postura, no entendimento dos autores, um atestado de ceticismo talvez melancólico. "A escrita de F. Hartog - mesmo na estrutura de conjunto de sua obra - parece, assim, animada de uma verdadeira nostalgia por uma concepção de história que faça dela, no presente, um dos discursos pelos quais o futuro se encontraria confrontado ou mesmo definido" ${ }^{47}$. Sua obra transmite um mal-estar que incide decisivamente na prática dos historiadores, pois a "crise do tempo" estaria manifesta igualmente como uma "crise atual na escrita da história". E é neste ponto que uma das críticas mais constantes sobre as reflexões de Hartog se mostra pertinente, pois toca na questão das relações entre regimes de historicidade e regimes historiográficos. Como sugere a resenha, "a noção de regime de historicidade convida, então, a reinterrogar a articulação entre estar na história (être dans l'histoire), o fazer da história (faire de l'histoire) e fazer história (faire l'histoire)". Questionam-se justamente as referências mútuas entre historicidade e historiografia, afinal, um regime de historicidade pode comportar formas distintas de escrita da história.

É certo que o problema não passou despercebido por Hartog, que já o indicava no artigo de sistematização da noção escrito conjuntamente com

46 Além dos textos elencados na nota 6, menciono aqui as seguintes resenhas: BENOIST, Stéphane. "Compte rendus". Revue Historique, n. 632, 2004, p. 843-846; BLOCKER, Déborah; HADDAD, Elie. "Le présent comme inquiétude: temporalités, écritures du temps et actions historiographiques". Revue d'Histoire Moderne et Contemporaine, n. 53, 2006, p. 160-169; HANNOUM, Abdelmajid. "What is an order of time?" History and Theory, n. 47, october 2008, p. 458-471. Ver ainda o esforço genealógico sobre a noção em DELACROIX, Christian. "Généalogie d'une notion”. In: DELACROIX, Christian; DOSSE, François; GARCIA, Patrick (sous la direction de). Historicités, op. cit., p. 29-45.

47 BLOCKER, Déborah; HADDAD, Elie. "Le présent comme inquiétude: temporalités, écritures du temps et actions historiographiques", op. cit., p. 168. 
Gérard Lenclud. Naquela oportunidade, ambos ressaltavam que "regime de historicidade e regime historiográfico não se situam exatamente sobre o mesmo plano". A questão, então, se situaria em diversas frentes: sobretudo "aquela do direito de se estabelecer uma equivalência, mesmo grosseira, entre consciência do passado e consciência histórica e a falar da história lá onde falta, talvez mais do que a sua escrita, o tipo particular de elaboração que definiria o gênero, e esta forma específica de interesse pelo passado ligado a ele"48. A indagação, todavia, não é levada a cabo nem neste artigo, nem no livro de 2003. Por mais que a noção não se pretenda homogênea e que, na sua formulação, estejam previstas "brechas" que tornam plurais e dinâmicos os regimes de historicidade, seja antigo, seja moderno, o problema das variações consideráveis dos regimes discursivos sobre a história demanda ainda uma reflexão mais ponderada.

Blocker e Haddad ressaltam também outra fragilidade na formulação sobre os regimes de historicidade: o não desenvolvimento das relações entre a dimensão individual, subjetiva e fenomenológica do tempo e a dimensão coletiva e sociológica da temporalidade. O que Hartog deixou de fazer, segundo o entendimento dos autores, é pensar justamente as articulações de escalas entre o indivíduo, tomado em sua subjetividade, e a sociedade encarada de forma mais ampla. Pois, em Regimes d'historicité, Hartog se vale de um procedimento analítico particular, que para alguns se constituiria como "estudo de caso": Ulisses, Sahlins, Santo Agostinho, Chateaubriand, mesmo indícios pontuais da cultura contemporânea são estudados. O que se questiona, nesse sentido, é a validade e mesmo a representatividade destes exemplos para a discussão de uma categoria com pretensões mais generalizantes. De acordo com o parecer da resenha, isto implicaria uma falta grave, já que "a escrita dos autores estudados parece assim compreendida fora de toda determinação social" ${ }^{49}$. Hartog comete, portanto, um primeiro pecado de ordem sociológica.

Este mesmo pecado é ressaltado por Abdelmajid Hannoum, no texto publicado na History and Theory, em 2008, "What is an order of time?". Lendo as colocações de Hartog, restou para Hannoum a curiosidade

48 HARTOG, François; LENCLUD, Gérard. "Regimes d'historicité". In: DUTU, Alexandre; DODILLE, Norbert. L'état des lieux en sciences sociales, op. cit., p. 26.

49 BLOCKER, Déborah; HADDAD, Elie. "Le présent comme inquiétude: temporalités, écritures du temps et actions historiographiques", op. cit., p. 165. 
de saber "qual foi a experiência [temporal] do camponês na França rural no tempo de Chateaubriand? Qual foi a experiência do homem e mulher comuns nas cidades?"50. O que na verdade está sendo colocado em dúvida é justamente a capacidade de a noção de regime de historicidade abarcar uma pluralidade de experiências de tempo. $\mathrm{O}$ autor ressalta ainda o fato de Hartog não ter mencionado nada sobre a historicidade medieval ou sobre as formas de temporalidade no mundo islâmico ("this is not the direction Hartog takes in his book"). Mas o âmago da crítica de Hannoum reside no uso feito no livro das considerações de Marshall Sahlins, as quais, segundo o autor, não se sustentam, tendo, inclusive, já sido questionadas dentro da própria antropologia.

Para Hannoum, Hartog não apenas desconsidera o debate no meio antropológico, como procede segundo premissas equivocadas. Sua falha se deve, sobretudo, ao fato de ter escolhido a "história intelectual" e não a "antropologia do tempo" para estabelecer as relações entre as tribos do Pacífico estudadas por Sahlins e o mundo antigo, articulados segundo um "regime heroico de historicidade" 51 . As diferenças entre as duas abordagens são assim descritas: "a antropologia do tempo olha para as experiências de tempo vividas em sociedades específicas e com referência a culturas específicas sem privilegiar uma experiência sobre outra. Uma história intelectual do tempo, principalmente praticada por Hartog, examina as articulações intelectuais do tempo por escritores, filósofos, historiadores, poetas etc.". Além disso, o olhar antropológico não diferencia grupos dominantes ou subalternos, enquanto que o historiador intelectual privilegia apenas as formulações filosóficas do tempo ${ }^{52}$.

Quanto ao segundo ponto, a postura do autor é evidente, levando-o inclusive a defender, ao final do artigo, que "ordens do tempo subalternas" possam ser escritas, de maneira a "completar" a abordagem de Hartog. Trata-se de algo, em tese, positivo, pois implica o trabalho e a reflexão sobre a categoria de regime de historicidade nos chamados subaltern studies. Já no

50 HANNOUM, Abdelmajid. "What is an order of time?" History and Theory, op. cit., p.

465 .

51 HARTOG, François. "Des îles d'histoire". In: Régimes d'historicité, op. cit., p.

$33-52$.

52 HANNOUM, Abdelmajid. "What is an order of time?" In: History and Theory, op. cit., p. 463. 
que diz respeito ao primeiro ponto, creio que as formulações de Hannoum tendem a criar uma dicotomia que, na obra de Hartog, não se coloca, qual seja, a separação entre o campo da experiência e o âmbito do discurso. Mesmo uma antropologia atenta aos princípios temporais que organizam seu saber não desconsidera o papel constitutivo dos discursos na apreensão das experiências de historicidade, levando inclusive a problematizar, na relação de tempo com o outro, "como a antropologia constrói o seu objeto" 53 . De todo modo, além do pecado sociológico já referido, Hartog aparece também pecando do ponto de vista antropológico, especificamente em uma forma de saber que organiza suas investigações desde o trabalho sobre Heródoto.

Por fim, cabe menção ainda ao importante texto de Christian Delacroix, que se pretende uma genealogia crítica da noção de regime de historicidade $^{54}$. Delacroix aponta o impacto, pelo menos no ambiente francês, que teve a noção. Em 1994, quando o editorial da revista Annales. Histoire, sciences sociales convidou a comunidade para refletir sobre um "tournant critique", a noção foi mobilizada como forma de legitimar o trabalho dos historiadores, por meio das questões do tempo e da historicidade, diante do campo mais vasto das ciências sociais. Para o autor, a noção, pretendida como um "instrumento heurístico", despontava como "um recurso 'teórico' privilegiado para definir a identidade historiadora" 55 .

Não obstante, há um perigo eminente, talvez mais no seu uso do que na sua formulação, que a categoria carrega. Pois, "a 'redução à heurística' da noção arrisca, por outro lado, ser uma maneira de desencorajar toda sua historicização: uma noção 'heurística' realça a metodologia que é o tradicional território de sinuosidade (territoire de repli) dos historiadores [...] e ela pode ser assimilada a um instrumento de conhecimento 'universal' escapando a toda determinação histórica”. O autor chega ainda a se

53 FABIAN, Johannes. Time and the other. How anthropology makes its object, op. cit.; ver ainda FABIAN, Johannes. Time and the work of anthropology. Critical essays 1971-1991. Harwood Academic Publishers, 1991.

54 DELACROIX, Christian. “Généalogie d'une notion”. In: DELACROIX, Christian; DOSSE, François; GARCIA, Patrick (sous la direction de). Historicités, op. cit., p. 29-45.

55 Ibid., p. 30. Ver ainda PASSERON, Jean-Claude. "História e sociologia-identidade social e identidade lógica de uma disciplina". In: . O raciocínio sociológico. Petrópolis: Vozes, 1995, p. 64-98; e DOSSE, François. "Questões suscitadas pela pluralidade dos modelos interpretativos em ciências sociais: a guinada interpretativa”. In: ___ A história à prova do tempo. Da história em migalhas ao resgate do sentido. São Paulo: Editora da Unesp, 2001, p. 39-70. 
perguntar se a formulação de tal noção não seria o produto de um regime específico de historicidade ${ }^{56}$. Ora, penso que a objeção diz respeito mais às maneiras pelas quais a noção pode ser instrumentalizada do que àquilo que ela carrega teoricamente. Afinal, a forma pela qual Hartog parece articulá-la, nessas "idas e vindas no tempo", não deixa de impor precisões empíricas na sua dimensão conceitual. De todo modo, como Max Weber já advertiu, é próprio das noções, categorias e conceitos intentarem oferecer um princípio de generalização que torne possível a inteligibilidade no e sobre o tempo, sob pena de se redundar em um historicismo exacerbado por meio do qual cada época só pode ser compreendida dentro dela mesma ${ }^{57}$.

Outra colocação feita por Delacroix toca, de forma mais sofisticada, naquilo que Blocker e Haddad já haviam mencionado, ou seja, a relação entre o individual e o social. Aqui, contudo, trata-se das relações entre tempo subjetivo e tempo objetivo ou, em outras palavras, na tensão entre os aspectos epistemológicos da discussão e seus aspectos ontológicos. A questão da historicidade se desdobra tanto nas formas de produção de um saber historiográfico quanto nas formas possíveis de consciência histórica. De modo equivalente ao que já foi ressaltado, o que se cobra é um desenvolvimento mais detalhado das relações entre regime de historicidade e regime historiográfico:

Onde se reencontram as dificuldades de gestão do dualismo historicidade objetiva/consciência histórica e/ou historiográfica, recorrentes no trabalho de Hartog sobre a noção e do qual fazemos a hipótese que elas são os marcadores, ao mesmo tempo, dos limites deste trabalho, mas também de suas potencialidades de desenvolvimento ulteriores em termos de análise empírica ${ }^{58}$.

Ou seja, trata-se aqui de um pecado propriamente historiográfico, pois, na verdade, é o hiato entre a categoria e a experiência, de um lado e,

56 Ibid., p. 33.

57 Sobre a tarefa de conceituação, remeto, entre outros, a WEBER, Max. "L'objectivité de la connaissance dans les sciences et la politique sociales". In: . Essais sur la théorie de la science. Paris: Plon, 1965.

58 DELACROIX, Christian. "Généalogie d'une notion”. In: DELACROIX, Christian; DOSSE, François; GARCIA, Patrick (sous la direction de). Historicités, op. cit., p. 38. 
de outro, entre a concepção teórica do tempo e os aspectos práticos da escrita da história o que se postula como objeção. Consequência fundamental disso é se tratar ainda de uma noção vaga e incerta que acaba por contaminar inclusive a noção que lhe é correlata, isto é, a ideia de presentismo. Não obstante, Delacroix termina seu artigo convidando à reflexão, mas de forma um tanto irônica e provocativa: "este uso 'frouxo' (lâche) e pouco tematizado das noções não é, depois de tudo, característico do trabalho dos historiadores?" 59

\section{VIII.}

Três pecados e um único pecador. Hipotética, instrumental, modesta, a referida noção certamente não se pretende um conceito homogêneo e universal. Ela não explica os momentos de crise, ela não fornece soluções propícias, nem tampouco engendra propostas ou prognósticos para um novo tempo, marcando ainda certo pessimismo, mas um pessimismo responsável. Seu mérito e sua utilidade residem antes na sua capacidade em conceituar o tempo, torná-lo, de uma forma bastante particular, pensável e, sobretudo, representável. Dizer o tempo, pensar a história, tal me parece sua profunda e pertinente contribuição. Mas também dizer o presente, pensar o presente, situá-lo no tempo. As ideias de presentismo, como todas as suas fragilidades, são ainda uma formulação inquietante e que, por isso, aguçam a curiosidade. Por isso que a ideia de um regime de historicidade presentista incita à reflexão, mesmo que seja para colocar ali dúvidas quanto a sua validade. Afinal, elaborada diante de uma situação em que história, memória e presente assumem conotações sensivelmente distintas das nossas, como é a realidade francesa contemporânea, de que forma projetar essa contribuição para o nosso contexto particular?

A própria pretensão deste artigo, voltado para parte da obra de um historiador no pleno vigor de sua produção intelectual, não é ela também sinal dessa urgência do tempo; do anseio de tratá-lo, o tempo, na mesma

59 Ibid., p. 43. 
medida imponderável em que ocorre? Talvez sim, mas há outras razões plausíveis para tanto. Pois é como se não pudesse nem devesse deixar para depois, sob o perigo de o debate perder sua atualidade (seria isso, de fato, possível num regime presentista, onde a atualidade é um dado da permanência?) e ficarmos ainda a reboque de discussões requentadas e apenas forçosamente pertinentes. A situação parece caminhar para o outro lado, é verdade, para o centro do debate, já que os eventos do nosso passado recente, que retornam na difícil fronteira entre a "justa memória" e a verdade histórica, demandam respostas imediatas por parte dos historiadores e da sociedade em geral, que chegaram na forma de imperativos legais, morais e historiográficos: abrir os arquivos, reconhecer as culpas, reparar os crimes, defender as vítimas, refutar as imposturas, recusar o esquecimento, respeitar a memória, escrever a história... O presente, qualquer que seja ele, se impõe à reflexão para os historiadores se não pela dimensão ética que o impregna, ao menos pela importância epistemológica que ele assim delimita.

Recebido em abril de 2010. Aprovado em abril de 2010. 